\title{
Coseismic deformation due to the 2007 Chuetsu-oki earthquake $\left(M_{\mathrm{w}}=6.8\right)$
}

\author{
Yosuke Aoki ${ }^{1}$, Masato Furuya $^{2}$, and Teruyuki Kato ${ }^{1}$ \\ ${ }^{1}$ Earthquake Research Institute, University of Tokyo, Tokyo 113-0032, Japan \\ ${ }^{2}$ Department of Natural History Sciences, Hokkaido University, Kita-ku, N10W8, Sapporo 060-0810, Japan \\ (Received December 19, 2007; Revised June 7, 2008; Accepted June 9, 2008; Online published November 18, 2008)
}

\begin{abstract}
Global Positioning System (GPS) and Synthetic Aperture Radar Interferometry (InSAR) detected substantial ground deformation due to the 2007 Chuetsu-oki earthquake $\left(M_{\mathrm{w}}=6.8\right)$; GPS observation detected a horizontal deformation of up to about $170 \mathrm{~mm}$ and subsidence of up to $30 \mathrm{~mm}$, and InSAR detected up to $290 \mathrm{~mm}$ of line-ofsight changes. A fault model is proposed to fit the ground deformation field as well as the aftershock distribution. Our model shows that a northwest-dipping fault to the north and a southeast-dipping fault to the south, consistent with the aftershock distribution, fits well with the observed data. However, our model also suggests that the modeled faults are likely to extend to shallower depths, where aftershocks are terminated. Combining our model with the subsurface structure suggests that the earthquake rupture initiated at depth and propagated into shallower depths that are not capable of nucleating an earthquake because of the presence of unconsolidated sediments.
\end{abstract}

Key words: Coseismic deformation, Global Positioning System, Synthetic Aperture Radar, Interferometry.

\section{Introduction}

Geodetic data have been widely used to detect and explore details of ground deformation associated with large earthquakes and their afterslips. In particular, the emergence of the continuous Global Positioning System (GPS) network allows us to delineate the deformation field due to earthquakes with high spatial as well as temporal resolution (e.g., Segall and Davis, 1997). Furthermore, synthetic aperture radar interferometry (InSAR) gives us further enhanced spatial resolution of ground deformation (e.g., Bürgmann et al., 2000). In particular, the launch of the ALOS satellite yields L-band synthetic aperture radar (SAR) images from PALSAR (Phased Array type L-band Synthetic Aperture Radar), allowing much better coherence than those imaged from C-band satellites even in heavily vegetated regions, such as Japanese islands, where C-band satellites do not work well (Rosenqvist et al., 2007). Geodetic data provide an independent estimate of fault slip distribution from that inferred from analyses of seismic waves. A comparison of these two data sets enables the detection of slipped areas during an earthquake without radiating seismic waves, thereby gaining more insights into regional seismic hazard assessment. Here, we propose a fault model for the coseismic deformation field associated with the 2007 Chuetsu-oki earthquake $\left(M_{\mathrm{w}}=6.8\right)$, using continuous GPS and L-band InSAR data. While our model is derived with a reference to the detailed aftershock data published by Kato et al. (2008), the geodetic data show that the fault slip area extends to shallower depths where no aftershocks were detected.

The Chuetsu-oki earthquake occurred on July 16, 2007 near a diffuse plate boundary between the Eurasian and

Copyright (c) The Society of Geomagnetism and Earth, Planetary and Space Sciences (SGEPSS); The Seismological Society of Japan; The Volcanological Society of Japan; The Geodetic Society of Japan; The Japanese Society for Planetary Sciences; TERRAPUB.
North American (or Okhotsk) plates (Fig. 1) with a relative convergence rate of approximately $10 \mathrm{~mm} / \mathrm{yr}$ (e.g., Heki et al., 1999). The continuous GPS network shows that the region is characterized by diffuse east-west compression (Sagiya et al., 2000), although vertical deformation is insignificant (Aoki and Scholz, 2003). The region has experienced several large earthquakes including the 1964 Niigata earthquake ( $M=7.5$; e.g., Ruff and Kanamori, 1983) and the 2004 Mid Niigata Prefecture earthquake $(M=6.8$; Hirata, 2005), both of which have thrust focal mechanisms, consistent with the regional tectonic setting there.

The subsurface structure in the focal area of the Chuetsuoki earthquake is known to be complicated from previous studies. It is characterized by active folding and a thick sedimentary layer. High-resolution seismic tomography reveals that seismic velocities at depths shallower than $8 \mathrm{~km}$ are anomalously slow in the focal area of the $2004 \mathrm{Mid} \mathrm{Ni}$ igata Prefecture earthquake, $40 \mathrm{~km}$ southeast of that of the Chuetsu-oki earthquake (Kato et al., 2006). Also, Sato and Kato (2005) found an active folding structure in the focal area of the 2004 Chuetsu earthquake. This type of subsurface structure may complicate the regional stress field, resulting in a complex signature of seismic activity. Indeed, Kato et al. $(2007,2008)$ showed that the aftershock distribution associated with both the Mid Niigata Prefecture and Chuetsu-oki earthquakes does not represent a single plane, implying that multiple fault planes are responsible for generating both of these earthquakes. Kato et al. (2008) precisely relocated aftershocks of the Chuetsu-oki earthquake, suggesting that two conjugate fault planes are responsible; they also suggest that a northwest-dipping fault is responsible in the northern part, near the hypocenter and that a southeast-dipping fault is responsible to the south. We will model the observed deformation field with reference to the aftershock distribution derived from dense temporally seis- 


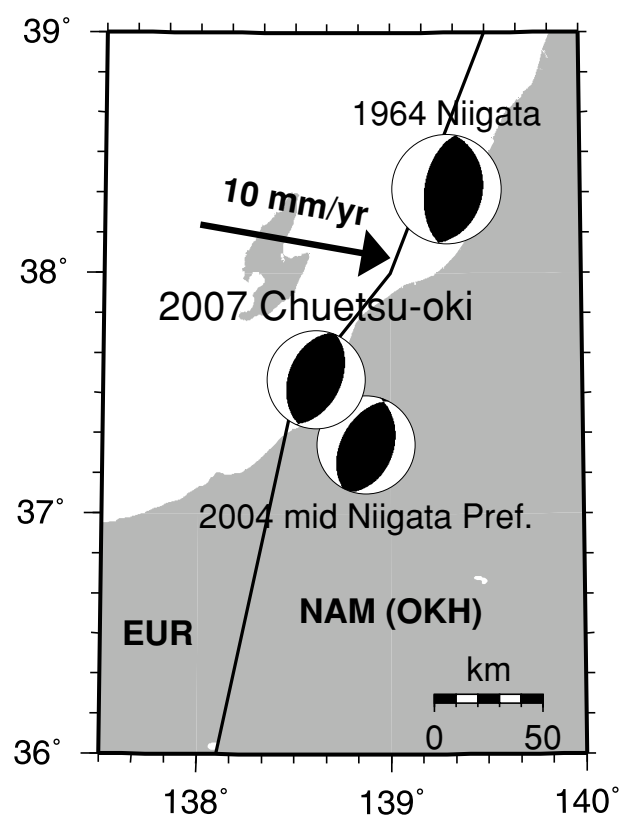

Fig. 1. Tectonic setting of the focal area of the 2007 Chuetsu-oki earthquake and its vicinity. Notable earthquakes in the area for the last 50 years are appended with their focal mechanisms. EUR, NAM, and OKH represent the Eurasian, North American, and Okhotsk plates, respectively.

mic observations (Kato et al., 2008).

\section{Data}

We used GPS and InSAR data in the analysis. This section provides some details of these data.

\subsection{GPS}

The Geographical Survey Institute of Japan operates a continuous GPS network in the Japanese islands (Sagiya, 2004). Each GPS site samples data every $30 \mathrm{~s}$ and calculates the coordinate once a day. We took a 5-day average of the coordinate of each site before (July 11-15, 2007) and after (July 17-21, 2007) the earthquake, and the difference of these two is used as coseismic deformation. There are 45 GPS sites in the area, but two sites near the epicenter were removed from the analysis because GSI announced that the data from these sites are perturbed by local deformation due to the earthquake shaking. We therefore used 43 GPS sites in the present analysis.

Figure 2 shows the horizontal coseismic deformation field. Most of the GPS sites move northwestward, consistent with the thrust faulting mechanism inferred from seismic wave analysis (e.g., Hikima and Koketsu, 2007). The observed displacement is larger near the epicenter, up to $170 \mathrm{~mm}$. The vertical deformation was also observed with a maximum subsidence of about $30 \mathrm{~mm}$ near the coast, which is also consistent with a deformation field produced by a thrust earthquake.

Uncertainties of each component of each site are estimated by the repeatability of daily solutions between July 1 and 15, 2007. We did not assume a correlation between components nor sites. Typical values of uncertainties are 2 , 4 , and $10 \mathrm{~mm}$ for the east, north, and vertical components, respectively.

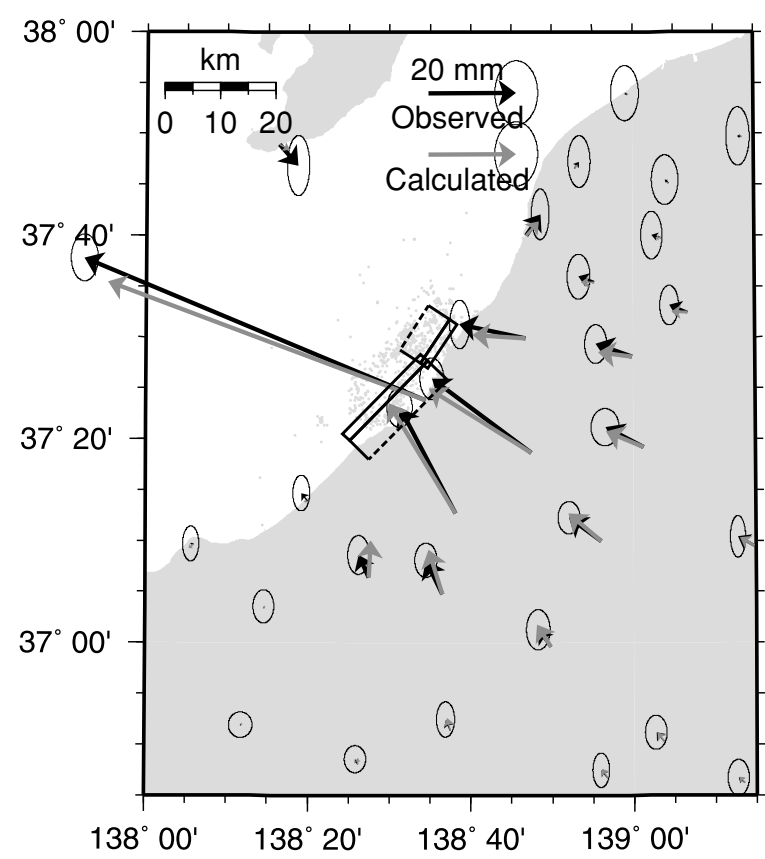

Fig. 2. Comparison of observed (black) and calculated (gray) horizontal displacements of continuous GPS sites. Error ellipses denote 95\% confidence bounds of the horizontal deformation. Modeled faults are denoted by thick and dashed lines, where dashed lines represent the bottom of the faults. Epicenters of aftershocks (Kato et al., 2008) are also shown by gray dots.

\subsection{InSAR}

Two PALSAR images taken on January 16 and July 19, 2007, respectively, both with the FBS (fine beam single) mode, were used to generate a coseismic InSAR image, whose perpendicular baseline was $297 \mathrm{~m}$ around the middle of the image. These images are taken from the descending orbit, thus the line-of-sight (LOS) is from $\mathrm{N} 100.11^{\circ} \mathrm{E}$, as shown in Fig. 3(a). The incidence angle is $38.78^{\circ}$ from vertical. Thus, the LOS change $d L$ is given by $d L=$ $-0.6167 u_{\mathrm{e}}+0.1099 u_{\mathrm{n}}-0.7795 u_{\mathrm{v}}$, where $u_{\mathrm{e}}, u_{\mathrm{n}}$, and $u_{\mathrm{v}}$ represent the east, north, and vertical component of the displacement, respectively. The orbit of the satellite was refined using the unwrapped interferogram and the Digital Elevation Map to increase the reliability of our result in longer wavelengths. Although there are several images taken from the ascending orbit which could better constrain the deformation field when combined with the images from the descending orbit, we did not use them in the present analysis in order to reject a possible contribution from postseismic deformation. Because the deformation field taken from a different orbit could well constrain the fault model, the images taken from the ascending orbit should be used in a future study after separating postseismic deformation from the observed deformation field.

Figure 3(a) shows the observed coseismic LOS changes, indicating large LOS changes near the coast. Coastal areas in the northern part exhibit negative LOS changes up to $300 \mathrm{~mm}$, whereas the southern part exhibits positive LOS changes up to $200 \mathrm{~mm}$. Figure 3(a) shows LOS changes only where the coherence is high enough (the lower threshold is 0.6 in this case) - that is, areas of low coherence are masked by gray in Fig. 3(a). With a viewpoint that the re- 
(a) Observed

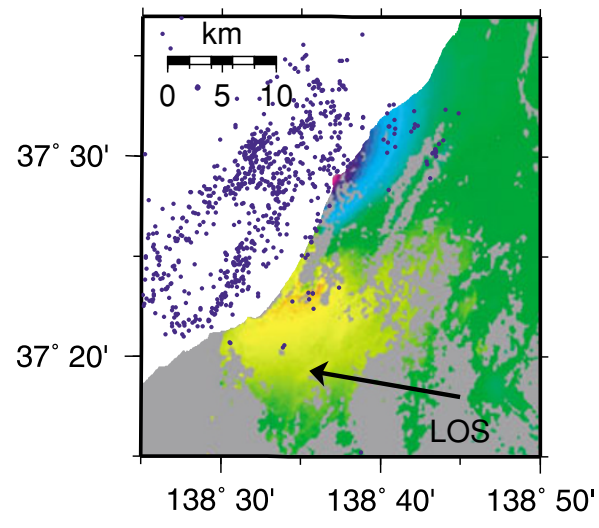

(b) Calculated

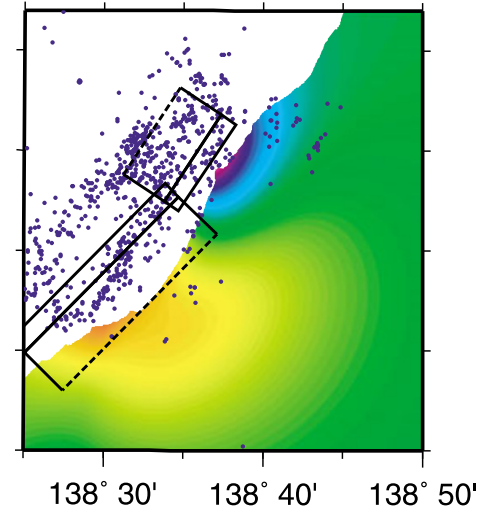

(c) Residual

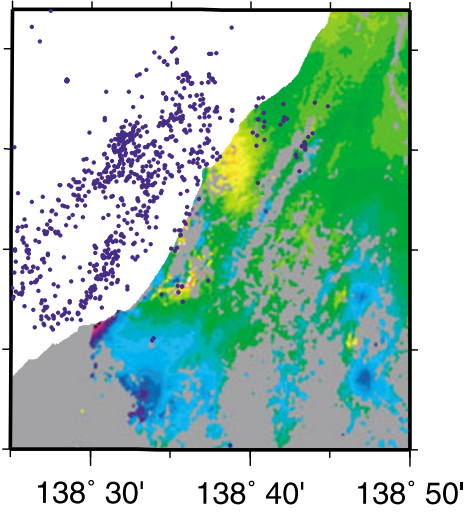

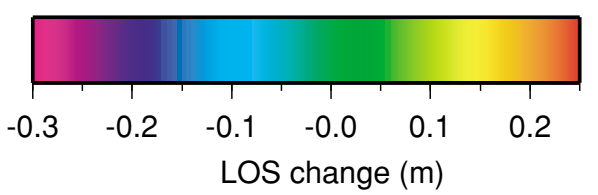

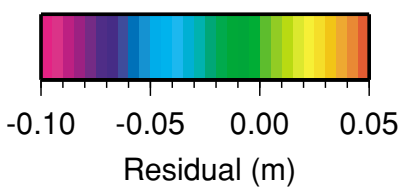

Fig. 3. (a) Observed line-of-sight (LOS) changes with epicenters of aftershocks (Kato et al., 2008) shown by blue dots. The direction of LOS is shown by a black vector. (b) Calculated LOS changes with aftershock distribution (Kato et al., 2008) and modeled faults with black solid and dashed lines, where dashed lines represent the bottom of the faults. (c) Difference between observed and calculated LOS changes with aftershock distribution (Kato et al., 2008). Note that the color scale is different from the other two panels.

duction of coherence is generally due to a change in surface properties, the low coherence inland is due to snowfall in the master image (January 16). The areas of low coherence near the focal region, where snow falls less frequently (Shoji and Kitaura, 2006), is likely due to liquefaction by the strong motion, consistent with on-site observations (e.g., Cyranoski, 2007; Normile, 2007).

As the interferogram of the two images mentioned above has 9 million points, resulting in computational difficulty when all the data are employed in the analysis, we need to reduce the number of data points without losing significant information. We employed the quadtree decomposition method (e.g., Samet and Webber, 1988), which has also been used in the InSAR data analysis (Jónsson et al., 2002). The quadtree decomposition divides the scene into four quadrants, and the mean and standard deviation of each quadrant are then calculated. If the standard deviation exceeds the specified threshold (20 $\mathrm{mm}$ in this case), the quadrant is further divided into four quadrants, and the process is iterated until the standard deviation is within the threshold. This process resulted in 262 data points representing the interferogram. The main objective of this process is that the data points are denser in areas of the high spatial LOS gradient. Note that the minimum spacing of the data points is about $100 \mathrm{~m}$.

Uncertainties of LOS displacements inferred from the interferogram are hard to assess. The error and its spatial correlation in InSAR data are controlled by various factors, including the baseline length of the orbit pair and atmospheric disturbance, but how they contribute to the error is enigmatic. Here we take the error to be $20 \mathrm{~mm}$, and no spatial correlation is assumed, although the error in InSAR data is obviously spatially correlated (e.g., Lohman and Simons, 2005). We neglect the spatial correlation in this study to simplify the calculation and because the deformation sig- nal is so large that spatially correlated error does not play a significant role in the data analysis.

\section{Modeling}

Here we attempt to model the observed deformation field assuming rectangular faults with uniform slip in each fault in an elastic, homogeneous, and isotropic halfspace. We estimate length, width, depth at the top, dip angle, strike, horizontal position (two parameters), and amount of slip (strike and dip components) for each fault to best fit the observed deformation. Given these parameters, the deformation field is calculated by Green's function of Okada (1985). Because of the nonlinear relationship between the fault parameters and deformation field, we need to solve a nonlinear optimization problem. Here we employed the Simulated Annealing inversion (Basu and Frazer, 1990), which has been applied to geodetic inversions (e.g., Cervelli et al., 2001) to find the optimum model parameters that minimize the weighted root mean square residual

$$
\chi^{2}=\frac{1}{N-p} \sum_{i=1}^{N}\left(\frac{d_{i}^{\mathrm{obs}}-d_{i}^{\mathrm{cal}}}{\sigma_{i}}\right)^{2}
$$

where $d_{i}^{\text {obs }}$ and $d_{i}^{\text {cal }}$ are observed and calculated data, $\sigma_{i}$ is standard deviation of the data, $N$ is the number of data, and $p$ is the number of model parameters, respectively. The subscript $i$ denotes $i$ th data. The Simulated Annealing algorithm searches the optimum model parameters randomly within the specified bounds which are narrowed according residuals as the search goes. It thus has the advantage of being independent on initial values, unlike psuedo-linear inversions, as well as computationaly inexpensive, unlike the grid search algorithm.

The aftershock distribution derived from a dense seismic observation reveals a complicated signature, with a 
northwest-dipping plane to the north and a southeastdipping plane to the south (Kato et al., 2008). It also indicates that the aftershocks are limited at depths deeper than approximately $8 \mathrm{~km}$ (Kato et al., 2008). With this point of view, we attempted to model the deformation field with five models; these are (1) a northwest-dipping fault with a top depth of $8 \mathrm{~km}$ to be consistent with the aftershock distribution, (2) same as (1) except that the fault is southeastdipping, (3) a northwest and southeast-dipping faults, both with their top depths of $8 \mathrm{~km}$, (4) same as (3), except that the northwest-dipping fault has a subfault extending to shallow depths with the same location at the bottom and allowing the dip change, and (5) same as (4) except that the southeast-dipping fault also has a subfault.

\section{Results}

Table 1 compares the fit to the data of different models by $\chi^{2}$ (Eq. (1)), indicating that $\chi^{2}$ roughly decreases as the number of model parameters increase. To determine if the increase in the number of model parameters gives the significant improvement of the fit to the data, we applied the $F$ test to all model pairs. This test shows that the best model is Model 5 with two southeast-dipping and northwest-dipping faults each. Because the top depths of the deeper faults are set to be $8 \mathrm{~km}$, the shallower limit of the aftershock distribution (Kato et al., 2008), our results demonstrate that the coseismic rupture has reached depths where no aftershocks occurred.

Table 2 shows the optimum parameters derived from the inversion, indicating that the southern (southeast-dipping) faults released a seismic moment twofold larger than that released from northern (northwest-dipping) faults. This is consistent with slip distribution inferred from strong motion analysis that more seismic moment has been released to the south during the earthquake (e.g., Hikima and Koketsu, 2007). Table 2 also indicates that the total moment derived from our geodetic modeling is comparable with that inferred from seismic wave analysis (e.g., Hikima and Koketsu, 2007), implying that aseismic slip is insignificant up to 5 days after the mainshock.

Figures 2 and 3 compare the observed and calculated deformation field for GPS and InSAR, respectively. Figure 2 shows that the horizontal displacements of almost all GPS sites are within the $95 \%$ confidence interval shown in Fig. 2 except for the closest GPS site. Figure 3 indicates that the

Table 1. Residuals of models with a single northwest dipping fault (Model 1), southeast-dipping fault (Model 2), a northwest- and southeast-dipping fault (Model 3), two northwest-dipping and a southeast dipping fault (Model 4), and two northwest and southeast dipping faults (Model 5). See text for details of the model. $\chi^{2}$ is computed by Eq. (1). $p$ represents the number of model parameters for each model. Subscripts represent the data used in the calculation of $\chi^{2}$.

\begin{tabular}{l|rccc}
\hline & $p$ & $\chi_{\text {GPS }}^{2}$ & $\chi_{\text {InSAR }}^{2}$ & $\chi_{\text {total }}^{2}$ \\
\hline Model 1 & 8 & 3.346 & 2.872 & 3.002 \\
Model 2 & 8 & 1.781 & 3.271 & 2.846 \\
Model 3 & 16 & 1.169 & 1.951 & 1.706 \\
Model 4 & 20 & 1.182 & 1.849 & 1.625 \\
Model 5 & 24 & 0.981 & 1.819 & 1.556 \\
\hline
\end{tabular}

Table 2. Fault parameters of the optimum model with two southeast-dipping and two northwest-dipping faults. Depth, Dip, Strike, Lat., and Lon. represent the depth at the top of each fault, dip angle from horizontal, strike clockwise from north, and latitude and longitude at the center of the top of each fault, respectively. $M_{\mathrm{W}}$ is calculated assuming the rigidity of $30 \mathrm{GPa}$.

\begin{tabular}{l|cc|cc}
\hline & \multicolumn{2}{|c|}{ SE dipping } & \multicolumn{2}{c}{ NW dipping } \\
& Deep & Shallow & Deep & Shallow \\
\hline \hline Length (km) & \multicolumn{2}{|c|}{20.31} & \multicolumn{2}{c}{9.60} \\
Width (km) & 5.33 & 6.24 & 6.25 & 2.22 \\
Depth (km) & 8.00 & 2.02 & 8.00 & 6.41 \\
& (fixed) & & (fixed) \\
Dip (deg.) & 21.32 & 73.40 & 46.60 & 45.78 \\
Strike (deg.) & \multicolumn{2}{|c|}{44.60} & \multicolumn{2}{c}{33.41} \\
Lat. (deg.) & 37.396 & 37.408 & 37.494 & 37.486 \\
Lon. (deg.) & 138.498 & 138.484 & 138.593 & 138.608 \\
Strike slip (m) & 0.01 & 0.10 & 0.19 & 0.86 \\
Dip slip (m) & 1.61 & 1.67 & 1.29 & 2.81 \\
\hline$M_{\mathrm{w}}$ & 6.38 & 6.47 & 6.18 \\
\hline Total $M_{\mathrm{w}}$ & \multicolumn{3}{|c}{6.75} \\
\hline
\end{tabular}

observed LOS changes (Fig. 3(a)) agree well with the calculated LOS changes (Fig. 3(b)). The difference between the calculated and observed LOS changes (Fig. 3(c)) indicates that the residual is large to the south by up to $100 \mathrm{~mm}$. This may be due to the simplification of the fault geometry and the slip distribution on the fault in our model. Nonetheless, we firmly believe that a simple model like ours still fits well the observed deformation.

\section{Discussion}

Figure 4 compares the location of aftershock distribution (Kato et al., 2008) and our fault model, clearly indicating that the southeast-dipping fault is significantly shallower than the aftershocks despite our effort to set the modeled faults at depths similar to those of the aftershocks. A possible reason for this discrepancy is an anomalously thick sedimentary layer in this region (Kato et al., 2006). Although geodetic data are generally much less sensitive to the crustal structure than seismic data, incorporating a heterogeneous crustal structure could change the optimum source location by up to several kilometers (e.g., Du et al., 1997). Another possibility is that the heterogeneous slip distribution on a fault, ignored in this study, can correct the bias. Our statistical analysis revealed that increasing the number of model parameters significantly improves the model (Table 2), implying that the slip distribution is likely to be heterogeneous or, at least, cannot actually be approximated by uniform slip on a fault.

One of the most prominent features of our model is that the fault rupture is likely to extend to shallower depths where aftershocks are not observed, despite the recognition that the aftershock distribution generally indicates the size of the mainshock rupture. We attribute this discrepancy to be the anomalous subsurface structure in this area. Seismic surveys revealed that the area is characterized by a sedimentary layer as thick as about $5 \mathrm{~km}$ (Kato et al., 2006). This sedimentary layer has anomalously low seismic velocity structure (Kato et al., 2006), thus it likely yields a con- 
(a) Plan view

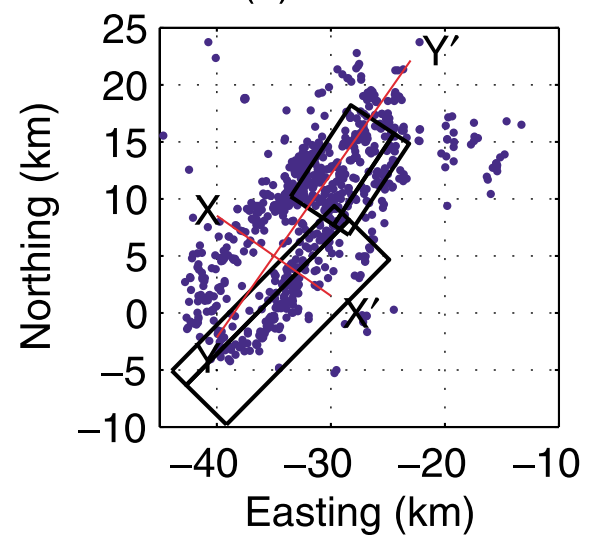

(b) $X-X^{\prime}$ cross section

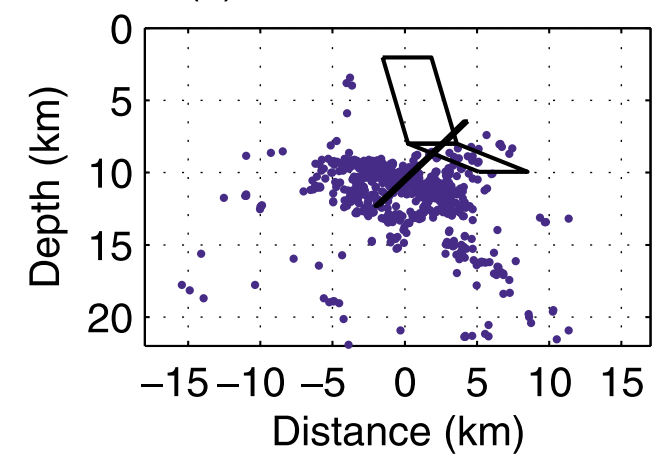

(c) $Y-Y^{\prime}$ cross section

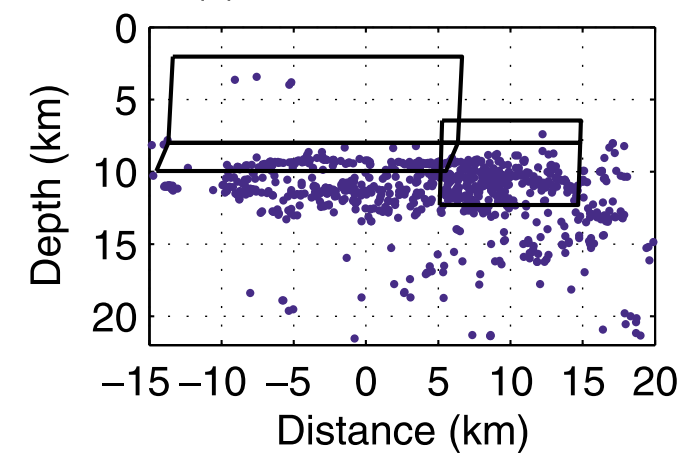

Fig. 4. Comparison between aftershock distribution (blue; Kato et al., 2008) and our preferred fault model (black). (a) Plan view. Red lines indicate the direction of cross sections in (b) and (c). (b) Cross section along $\mathrm{X}-\mathrm{X}^{\prime}$. (c) Cross section along $\mathrm{Y}-\mathrm{Y}^{\prime}$.

ditionally stable slip, inhibiting the nucleation of an earthquake and leading to the absence of aftershocks there. However, the mainshock nucleating at depth can extend to shallower depths with a velocity-strengthening property by dynamic loading induced by the slip at depth (Scholz, 2002).

\section{Conclusion}

We modeled the coseismic deformation associated with the 2007 Chuetsu-oki earthquake observed by continuous GPS and InSAR. We assumed northwest- and southeastdipping faults by referring to a precisely relocated aftershock distribution. Our model shows that the coseismic rupture has likely propagated at shallow depths where aftershocks are terminated. We interpreted the rupture prop- agation to occur from deep, where unstable slips occur, to shallow, where slips are conditionally stable, thus an earthquake cannot be nucleated. The location of our modeled fault is significantly shallower than the aftershocks. Possible reasons for the discrepancy are an ignorance of the heterogeneous subsurface structure and heterogeneous slip distribution, both of which we did not take into account in this study.

Acknowledgments. We thank Aitaro Kato for providing us with the hypocenters of aftershocks, the Geographical Survey Institute for access to GPS data. Reviews by Eric Fielding and an anonymous referee improved the manuscript. PALSAR level 1.0 data from the ALOS satellite are shared among PIXEL (Palsar Interferometry Consortium to Study our Evolving Land surface) and are provided from Japan Aerospace Exploration Agency (JAXA) under a cooperative research contract with Earthquake Research Institute, University of Tokyo. The ownership of PALSAR data belongs to the Ministry of Economy, Trade, and Industry, and JAXA. This work was partially supported from the Grant-in-Aid for Scientific Research, Japan Society for Promotion of Science (19340123).

\section{References}

Aoki, Y. and C. H. Scholz, Vertical deformation of the Japanese islands, 1996-1999, J. Geophys. Res., 108(B5), 2257, doi:10. 1029/2002JB002129, 2003.

Basu, A. and L. N. Frazer, Rapid-determination of the critical-temperature in Simulated Annealing inversion, Nature, 249, 1409-1412, 1990.

Bürgmann, R., P. A. Rosen, and E. J. Fielding, Synthetic aperture radar interferometry to measure Earth's surface topography and its deformation, Ann. Rev. Earth Planet. Sci., 28, 169-209, 2000.

Cervelli, P., M. H. Murray, P. Segall, Y. Aoki, and T. Kato, Estimating source parameters from deformation data, with an application to the March 1997 earthquake swarm off the Izu Peninsula, Japan, J. Geophys. Res., 106, 11,217-11,237, 2001.

Cyranoski, D., Quake shuts world's largest nuclear plant, Nature, 448, 392-393, 2007.

Du, Y., P. Segall, and H. Gao, Quasi-static dislocations in three dimensional inhomogeneous media, Geophys. Res. Lett., 24, 2347-2350, 1997.

Heki, K., S. Miyazaki, H. Takahashi, M. Kasahara, F. Kimata, S. Miura, N. F. Vasilenko, A. Ivashchenko, and K. D. An, The Amurian Plate motion and current plate kinematics in eastern Asia, J. Geophys. Res., 104, 24,147-24,155, 1999.

Hikima, K. and K. Koketsu, Source process of the 2007 Chuetsu-oki earthquake inferred from far field waveforms and strong motions, Seismol. Soc. Jpn. Fall Meeting, Abstract P1-085, 2007 (in Japanese).

Hirata, N., Introduction to the special section for the 2004 Mid-Niigata Prefecture Earthquake, Earth Planets Space, 57, i, 2005.

Jónsson, S., H. Zebker, P. Segall, and F. Amelung, Fault slip distribution of the $1999 M_{w} 7.1$ Hector Mine, California, earthquake, estimated from satellite radar and GPS measurements, Bull. Seismol. Soc. Am., 92, 1377-1389, 2002.

Kato, A., S. Sakai, N. Hirata, E. Kurashimo, T. Iidaka, T. Iwasaki, and T. Kanazawa, Imaging the seismic structure and stress field in the source region of the 2004 mid-Niigata Prefecture Earthquake: Structural zones of weakness, seismogenic stress concentration by ductile flow, J. Geophys. Res., 111, B08308, doi:10.1029/2005JB004016, 2006.

Kato, A. and The Research Team of aftershock observations for the 2004 mid-Niigata Prefecture Earthquake, High-resolution aftershock observations in the source region of the 2004 mid-Niigata Prefecture Earthquake, Earth Planets Space, 59, 923-928, 2007.

Kato, A., S. Sakai, E. Kurashimo, T. Igarashi, T. Iidaka, N. Hirata, T. Iwasaki, T. Kanazawa, and Group for the aftershock observations of the 2007 Niigataken Chuetsu-oki Earthquake, Imaging heterogeneous velocity structures and complex aftershock distributions in the source region of the 2007 Niigataken Chuetsu-oki Earthquake by a dense seismic observation, Earth Planets Space, 60, this issue, 1111-1116, 2008.

Lohman, R. B. and M. Simons, Some thoughts on the use of InSAR data to constrain models of surface deformation: Noise structure and data downsampling, Geochem. Geophys. Geosyst., 6, Q01007, 
doi:10.1029/2004GC000841, 2005.

Nomale, D., Quake underscores shaky understanding of ground forces, Science, 317, 438-439, 2007.

Okada, Y., Surface deformation due to shear and tensile faults in a halfspace, Bull. Seismol. Soc. Am., 75, 1135-1154, 1985.

Rosenqvist, A., M. Shimada, N. Ito, and M. Watanabe, ALOS PALSAR: A Pathfinder Mission for Global-Scale Monitoring of the Environment, IEEE Trans. Geosci. Remote Sensing, 45, 3307-3316, 2007.

Ruff, L. and H. Kanamori, The rupture process and asperity distribution of 3 great earthquakes from long-period diffracted P-waves, Phys. Earth Planet. Inter., 31, 202-230, 1983.

Sagiya, T., A decade of GEONET: 1994-2003-The continuous GPS observation in Japan and its impact on earthquake studies-, Earth Planets Space, 56, xix-xli, 2004.

Sagiya, T., S. Miyazaki, and T. Tada, Continuous GPS array and presentday crustal deformation of Japan, Pure Appl. Geophys., 157, 2303
2322, 2000

Samet, H. and R. E. Webber, Hierarchical data structures and algorithms for computer graphics. I. Foundamentals, IEEE Comp. Graphics Appl., 8, 48-68, 1988 .

Sato, H. and N. Kato, Relationship between geologic structure and the source fault of the 2004 Mid-Niigata Prefecture Earthquake, central Japan, Earth Planets Space, 57, 453-457, 2005.

Scholz, C. H., The mechanics of earthquakes and faulting, 2nd ed., $471 \mathrm{pp}$ Cambridge University Press, Cambridge, UK, 2002.

Segall, P. and J. L. Davis, GPS applications for geodynamics and earthquake studies, Ann. Rev. Earth Planet. Sci., 25, 301-336, 1997.

Shoji, T. and H. Kitaura, Statistical and geostatistical analysis of rainfall in central Japan, Comp. Geosci., 32, 1007-1024, 2006.

Y. Aoki (e-mail: yaoki@eri.u-tokyo.ac.jp), M. Furuya, and T. Kato 